\title{
IDENTIFIKASI GAYA KOREA DI INDONESIA SEBAGAI BAGIAN DARI GAYA BARAT
}

\author{
Yunita Fitra Andriana, Rully Darmawan, Achmad Haldani \\ Program Studi Magister Desain Fakultas Seni Rupa dan Desain \\ Institut Teknologi Bandung \\ Jl.Ganesha No.10 Bandung \\ tatohchan8687@gmail.com
}

\begin{abstract}
Abstrak: Saat ini fenomena budaya pop Korea mewabah di seluruh penjuru Asia dan bahkan dunia, begitupun di Indonesia. Makalah ini memaparkan hasil penelitian tentang identifikasi gaya korea di Indonesia sebagai bagian dari gaya barat. Penelitian ini menggunakan metode estetik khususnya analisis visual yang bersifat kualitatif. Metode ini digunakan untuk menjabarkan secara spesifik ciri dari gaya yang dianggap sebagai gaya Korea, gaya barat yang menjadi induk gayanya, serta gaya remaja Indonesia (studi kasus Jakarta dan Bandung serta entertainer Indonesia). Berdasarkan data dan hasil analisa, dapat dibuktikan bahwa terdapat misinterpretasi masyarakat Indonesia terhadap gaya yang dianggap sebagai gaya Korea. Gaya yang ditampilkan oleh para ikon budaya pop Korea sesungguhnya merupakan gaya barat dengan berbagai rekonstruksi tampilan yang disesuaikan dengan karakteristik Korea. Sedangkan gaya remaja Indonesia cenderung meniru hampir sama persis gaya para ikon budaya pop Korea yang populer di Indonesia.
\end{abstract}

Kata Kunci : kultur populer, the korean wave, k-pop, fashion

\begin{abstract}
Nowadays, Korean pop culture phenomenone has became widely popular across Asia, around the world, and also in Indonesia. This research uses aesthetic method, especially qualitative visual analysis. This method will be used for identifying specifically the fashion of Korean pop culture, western style and Indonesian teenager style (research case: Korean lover communities in Jakarta and Bandung and also Indonesian entertainers), what makes them different to another. Based on data and analysis, the conclusion is, there are misinterpretation among the Indonesian about the Korean style. This style is adopting the western style with some reconstruction, which is came out from the Korean characteristic it selfs. But for the Indonesian teenager's style, it is almost has no different with the Korean style.
\end{abstract}

Keywords: popular culture, the Korean wave, K-Pop, fashion

\section{PENDAHULUAN}

Popular culture atau pop culture, selanjutnya disebut sebagai budaya pop, merupakan hasil kebudayaan yang dikonsumsi oleh massa sehingga menjadikannya populer. Budaya pop juga dianggap sebagai sesuatu yang kontemporer dan bersifat sementara, namun perannya sebagai pembentuk pandangan baru di kalangan masyarakat tidak dapat dipungkiri. Menurut Sorapure (2001) budaya pop merupakan pengetahuan dan kegiatan yang dilakukan oleh sebuah kelompok dalam waktu tertentu. Karena memiliki kesamaan, budaya pop 
merefleksikan dan mempengaruhi gaya hidup masyarakat; dan karena budaya pop terhubung dengan waktu dan tempat tertentu maka budaya pop bersifat sementara, sesuatu yang berubah, dan seringkali menjadi awal perubahan.

Budaya pop yang saat ini tengah melanda berbagai negara terutama negaranegara di Asia adalah budaya pop yang berasal dari Korea Selatan. Korea saat ini tengah membentuk mainstream baru di berbagai negara melalui $K$-pop (musik pop Korea), serial drama, film dan video game. Kesuksesan budaya pop Korea ini terbukti dengan munculnya istilah "The Korean Wave" sebagai bentuk ungkapan seberapa besar pengaruh budaya pop yang disebarkannya.

Fenomena budaya pop Korea pun turut mewabah di Indonesia. Sejumlah entertainer yang secara visual meniru gaya boyband dan girlband dari Korea seperti 'SM*SH,' 'Princess' dan 'Cherry Belle' bermunculan. Selain itu, budaya pop Korea juga memunculkan sejumlah grup cover dance $K$-pop di banyak daerah di Indonesia. Mereka adalah para penggemar $K$-pop membentuk grup imitasi ikon pop Korea idola mereka, meniru gayanya, mengimitasi dance-nya dan juga mengadopsi gaya bicara serta perilaku mereka. Dalam hal ini, ikon K-pop telah menjadi trendsetter dalam trend fashion remaja Indonesia. Seperti yang diungkapkan oleh Malcolm Barnard (1996: h 11) fashion bukan hanya apa yang kita kenakan, tetapi fashion juga adalah apa yang kita lakukan.

Selain komunitas cover dance, di Indonesia muncul pula komunitas pecinta kebudayaan Korea yang didominasi oleh remaja. Mereka kerap melakukan kegiatan berkumpul bersama hanya untuk sekedar berbagi informasi atau mempelajari segala sesuatu bernuansa kebudayaan Korea. Bersama komunitasnya, para anggota ini pun bergaya ala ikon pop Korea idola mereka. Menariknya, gaya yang dianggap sebagai gaya Korea oleh masyarakat Indonesia sesungguhnya merupakan gaya barat, namun istilah 'gaya Korea' kerap digunakan dalam hingar bingar fenomena The Korean Wave. Hal ini memunculkan pertanyaan, batas-batas mana yang menjadi patokan seseorang atau sebuah komunitas bergaya ala Korea di mata masyarakat Indonesia? Penelitian ini diawali dengan hipotesa bahwa adanya misinterpretasi di kalangan masyarakat tanah air yang menyebutkan gaya yang sebenarnya merupakan hasil adopsi dari gaya barat ini sebagai gaya ala Korea. 


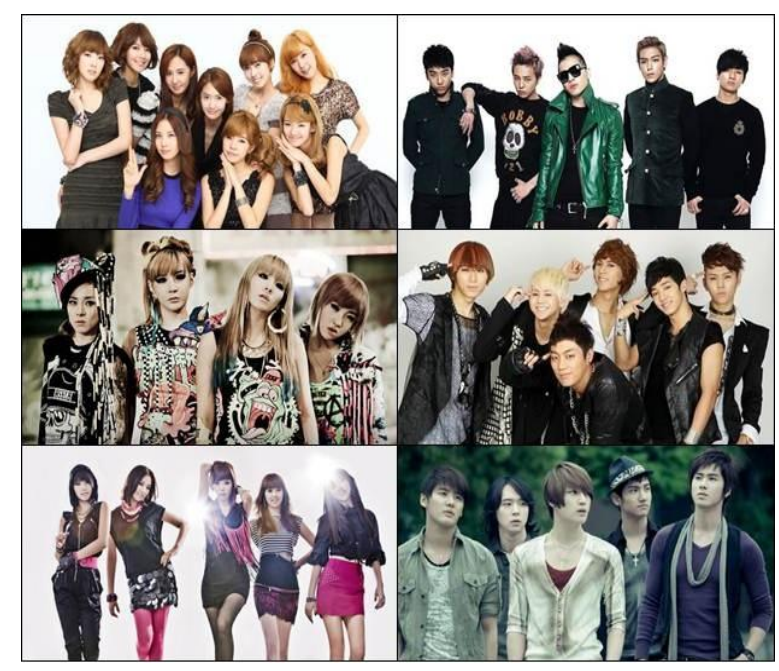

Gambar 1. Korean Girl Band dan Korean Boy Band (Sumber: http://azmynisca.blogspot.com diunduh pada 5 Desember 2012 pk. 12:32 WIB)

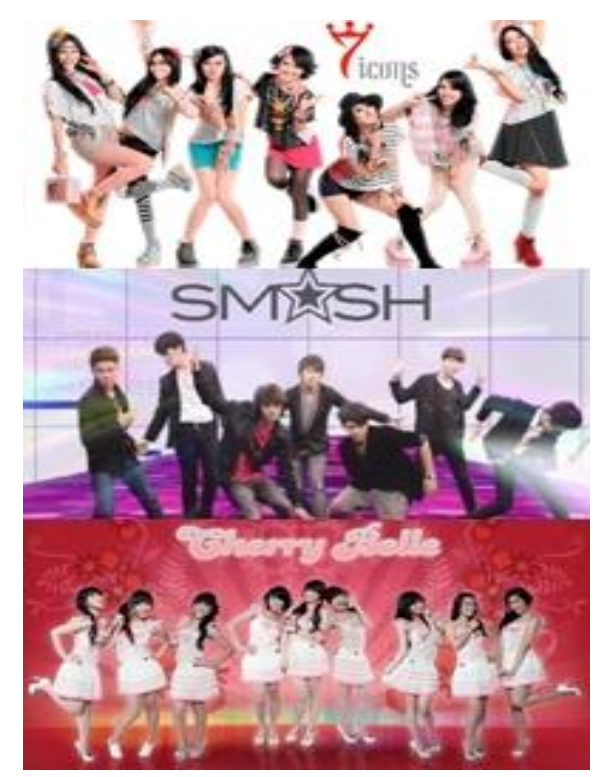

Gambar 2. Sejumlah boy band dan girl band Indonesia yang secara visual meniru tampilan boy band dan girl band Korea (Sumber: http://flashradiountirta.com/ diunduh pada 5 Desember 2012 pk. 14:03 WIB)

\section{METODE}

Penelitian ini menggunakan metode estetik, khususnya analisis visual yang bersifat kualitatif. Analisis visual yang dikaji dalam penelitian ini adalah gaya. Metode estetik yang diterapkan dalam penelitian ini berdasarkan teori-teori estetika, khususnya teori yang dikemukakan oleh A.A.M. Djelantik (1999) yang menyatakan bahwa gaya merupakan penonjolan yang setelah sangat menarik 
perhatian, cepat ditiru oleh pihak lain sehingga menjadikannya penonjolan milik bersama dan kita kenal dengan istilah 'style'. Walaupun tidak meniru persis seperti yang asli, dan masing-masing pihak sempat membuat penonjolan tersebut sesuai dengan kepribadiannya sendiri, dan karena itu bisa memberikan identitas tersendiri maka gaya mempunyai pengertian yang lebih individual. Dalam penelitian ini, penonjolan atau gaya tersebut ditampilkan pertama kali oleh gaya barat, lalu muncul kembali dalam tampilan gaya yang disebut gaya Korea oleh masyarakat Indonesia, dan lalu ditiru oleh remaja Indonesia.

Seperti yang juga dikemukakan oleh A.A.M. Djelantik (1999) bahwa unsur-unsur estetika terdiri dari wujud atau rupa, bobot atau isi, serta penampilan atau penyajian. Wujud merupakan apa yang terlihat oleh mata, terdiri dari bentuk dan struktur, dengan unsur-unsur bentuk yang terdiri dari titik, garis, bidang dan ruang. Lalu terdapat bobot yang merupakan unsur yang dihayati dan dirasakan, bukan hanya apa yang dilihat oleh mata. Gaya merupakan unsur yang berkaitan erat antara keduanya, tidak hanya apa yang terlihat atau wujud, tetapi juga berkaitan erat dengan bobot atau isi.

Objek dalam penelitian ini yaitu gaya, akan diidentifikasi berdasarkan unsur-unsur estetika pembentuknya, baik wujudnya yang terlihat oleh mata maupun bobot atau isinya yang tidak nampak oleh mata.

Pengolahan data untuk mengungkapkan gaya yang dianggap sebagai gaya Korea merupakan hasil adopsi dari gaya barat, akan dilakukan komparasi dengan pemecahan gaya seperti yang dilakukan oleh Takamura Zeshu dalam bukunya Roots of Streets Style, yang menjabarkan gaya berdasarkan ciri yang paling khas dan sumber adopsinya. Sedangkan dalam menjabarkan spesifikasi ciri beberapa gaya yang menjadi objek dalam penelitian ini, akan dilakukan dengan pendekatan unsur-unsur fashion berdasarkan teori Elaine Stone yang mengemukakan bahwa, komponen fashion terdiri dari siluet, detail, tekstur dan warna. Selain itu akan digunakan juga teori dari Gini S. Frings yang menyatakan bahwa elemen desain dalam desain fashion terdiri dari warna, bahan, garis, bentuk dan detail.

Selanjutnya hasil pengolahan data tersebut dapat menemukan batas-batas mana seseorang atau suatu komunitas dapat dikatakan bergaya ala Korea di mata 
masyarakat Indonesia. Selain itu juga menemukan sejauh mana gaya busana ala budaya pop Korea diadopsi oleh remaja Indonesia.

Budaya pop yang dikaji dalam penelitian ini adalah budaya pop Korea Selatan yang difokuskan pada K-pop (pop musik Korea). Fashion yang akan diteliti adalah fashion yang menjadi tampilan ikon $K$-pop, yaitu "Girls Generation" dan "Super Junior". Gaya barat yang akan dikaji dibatasi pada gaya yang ditampilkan oleh girlband dan boyband barat yang populer di Asia yaitu "Spice Girls" dan "Backstreet Boys." Sedangkan identifikasi fashion remaja Indonesia dibatasi dengan studi kasus komunitas pecinta Korea di kota Jakarta dan Bandung serta para entertainer Indonesia yang menampilkan gaya yang menyerupai entertainer dari Korea Selatan.

Kultur populer merupakan pembentuk mainstream di kalangan masyarakat. Seperti halnya kultur populer Korea yang saat ini tengah menghasilkan trend gaya baru di tengah-tengah remaja Indonesia. Trend gaya ala Korea ini membentuk selera dan pandangan baru bagi remaja Indonesia tentang cara berbusana, cara bicara dan bahkan cara bertingkah. Seperti yang diungkapkan oleh Malcolm Barnard dalam bukunya "Fashion Sebagai Komunikasi”(1996) fashion bukan hanya apa yang kita kenakan, tetapi fashion juga adalah apa yang kita lakukan.

Menurut Sorapure (2001) budaya pop merupakan pengetahuan dan kegiatan yang dilakukan oleh sebuah kelompok dalam waktu tertentu. Karena memiliki kesamaan, budaya pop merefleksikan dan mempengaruhi gaya hidup masyarakat; dan karena budaya pop terhubung dengan waktu dan tempat tertentu maka budaya pop bersifat sementara, sesuatu yang berubah, dan seringkali menjadi awal perubahan.

Pop culture melahirkan pop icon sebagai simbol, tokoh dan penggerak lajunya pop culture itu sendiri. Kepopuleran pop icon akan bertahan dalam jangka waktu tertentu yang cenderung singkat, namun efek mainstream yang dibentuk olehnya akan bertahan lebih lama. Korean pop icon yang paling berpengaruh dalam kesuksesan kultur Korea meraih popularitas seperti sekarang ini adalah para girl band dan boy band seperti Girls Generation, dan Super Junior. Gaya mereka kerap ditiru oleh para remaja Indonesia dan menghasilkan sejumlah entertainers yang disebut bergaya Korea seperti "SM*SH," "Cherry Belle" dan 
"Princess". Selain itu, komunitas seperti komunitas cover dance dan komunitas pecinta Korea pun bermunculan, para anggotanya kerap disebut bergaya ala Korea.

Berikut ini merupakan paparan data hasil observasi baik yang langsung maupun yang tidak langsung.

\section{Objek I}

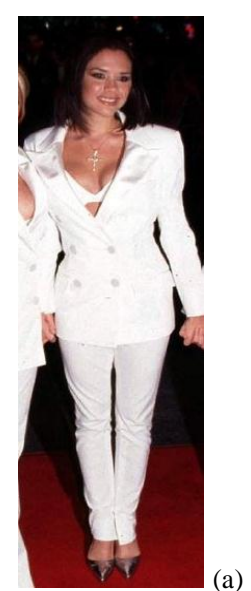

Girl Band barat asal Inggris "Spice Girls." (Sumber: www.posh24.com diunduh pada 6 Maret 2013 pk. 23:08 WIB)

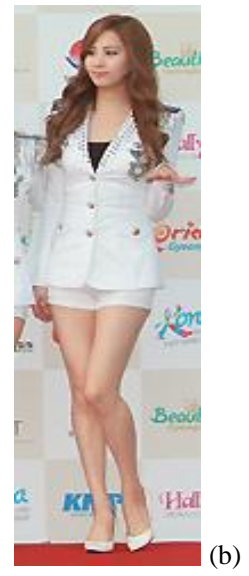

Girl Band Korea "Girls Generation." (Sumber: www.dkpopnews.net diunduh pada 10 Februari 2013 pk.11:48 WIB)

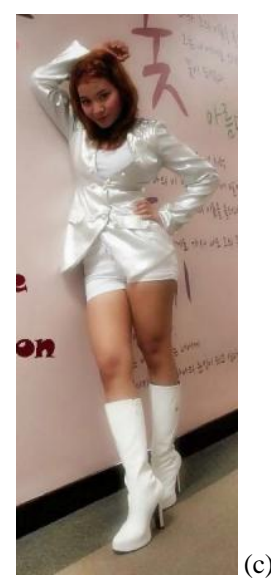

"SOICD" Grup Cover Dance Korea "Girls Generation." (Sumber: www.gurupop.com diunduh pada 5 Desember 2012 pk. 12:27 WIB)

Gambar 3. Perbandingan antara gaya barat, gaya yang disebut sebagai gaya Korea, serta gaya remaja Indonesia yang mengadopsi gaya ikon $K$-pop

\section{Objek II}

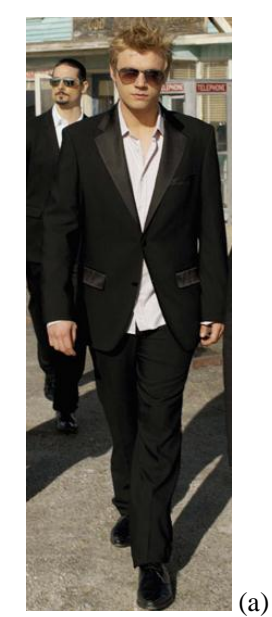

Boy Band barat asal

Amerika "Backstreet Boys."

(Sumber: www.ourstage.com diunduh pada 6 Maret 2013 pk. 17:41 WIB)

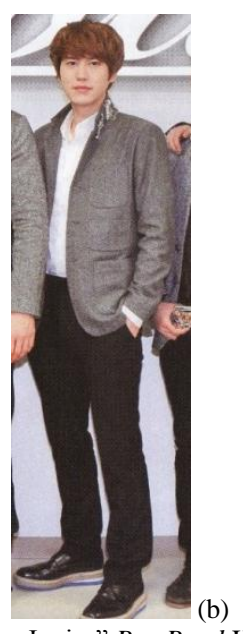

"Super Junior" Boy Band Korea (Sumber:icepluscoffee.wordpress.com diunduh pada 15 Maret 2013 pk. 21:31 WIB )

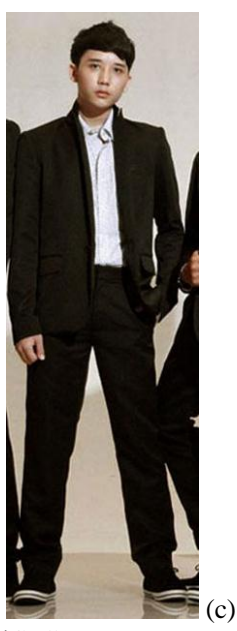

"SM*SH" Boy Band Indonesia.

(Sumber:photopoto.blogspot.com diunduh pada 15 Maret 2013 pk. 22:30 WIB)

Gambar 4. Perbandingan antara gaya barat, gaya yang disebut sebagai gaya Korea, serta gaya remaja Indonesia yang mengadopsi gaya ikon $K$-pop 
Asumsi awal yang mengemukakan bahwa gaya yang selama ini disebut sebagai gaya Korea oleh masyarakat Indonesia sesungguhnya merupakan gaya yang mengadopsi gaya barat, dapat dibuktikan dengan mengidentifikasi ciri serta perbedaan dari ketiganya. Pengidentifikasian ini dapat menjawab pertanyaan mengenai batas-batas mana yang menjadi patokan seseorang atau sebuah komunitas bergaya ala Korea di mata masyarakat Indonesia?

\section{HASIL DAN PEMBAHASAN}

Objek I. a

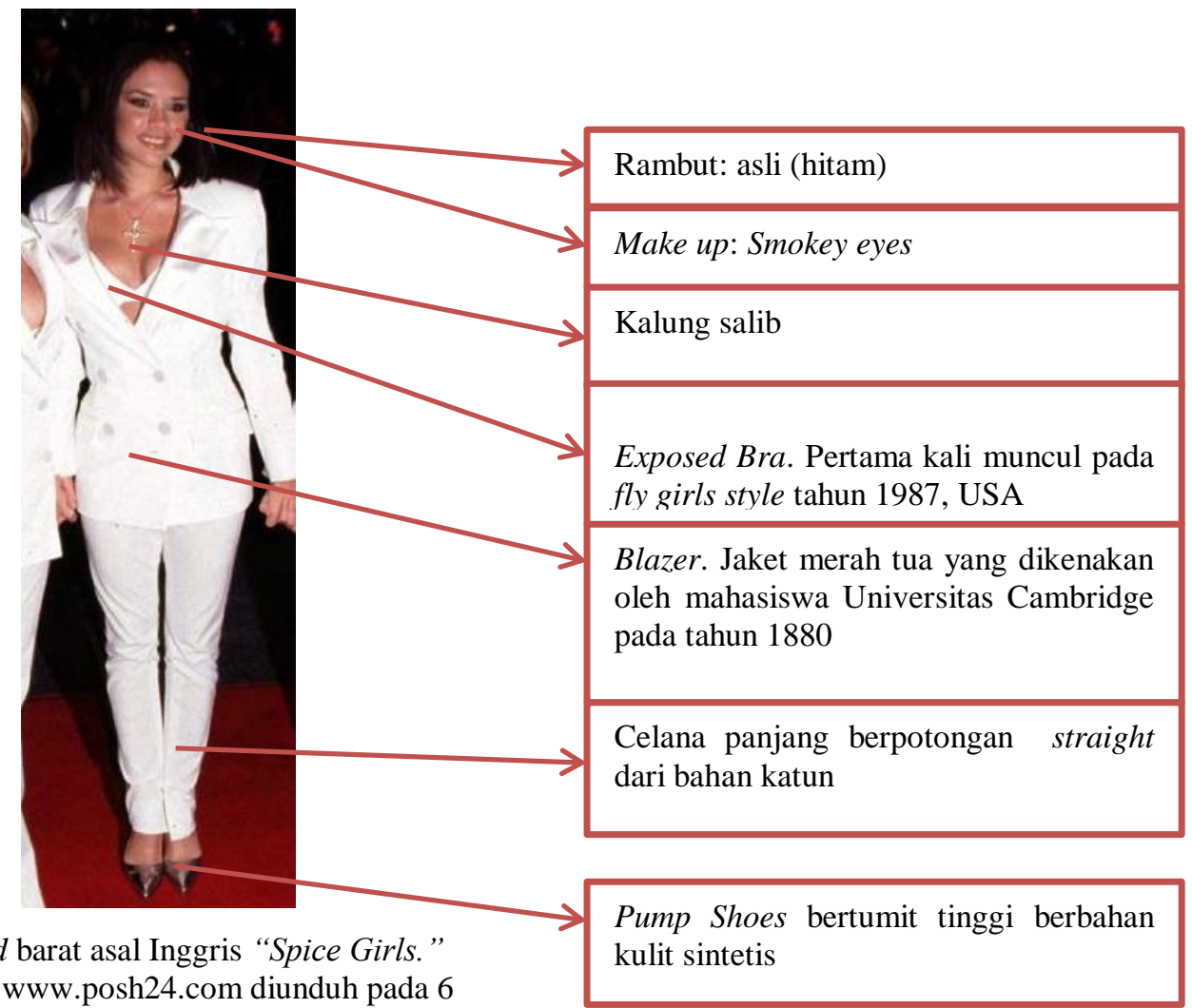

Girl Band barat asal Inggris "Spice Girls." Maret 2013 pk. 23:08 WIB)

Analisis :

1. Component of Fashion:

Silhouette/ Siluet:

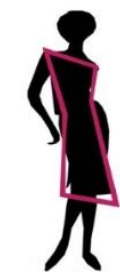

a. Details/ Detail: Bra
Milineris dan Aksesoris:

- Sepatu: Pump Shoes bertumit tinggi dari bahan kulit sintetis

- Kalung salib dari logam

b. Texture/ Tekstur:

Bra: halus, lembut. lunak Blazer: kaku, tebal, mengkilap

Celana Panjang: kaku, tebal, mengkilap

c. Color/ Warna:

2. Element of Designs:

a. Fabric/ Bahan: 
Blazer:

- Kerah: Tailor

- Lengan: Straight

- Saku:

- Opening/Closing: Di depan, dengan kancing

Celana Panjang:

- Opening/Closing: Di depan, dengan zipper dan kancing
Bra: Katun

Blazer: Katun tebal

Celana: Katun tebal

\section{Objek I. b}

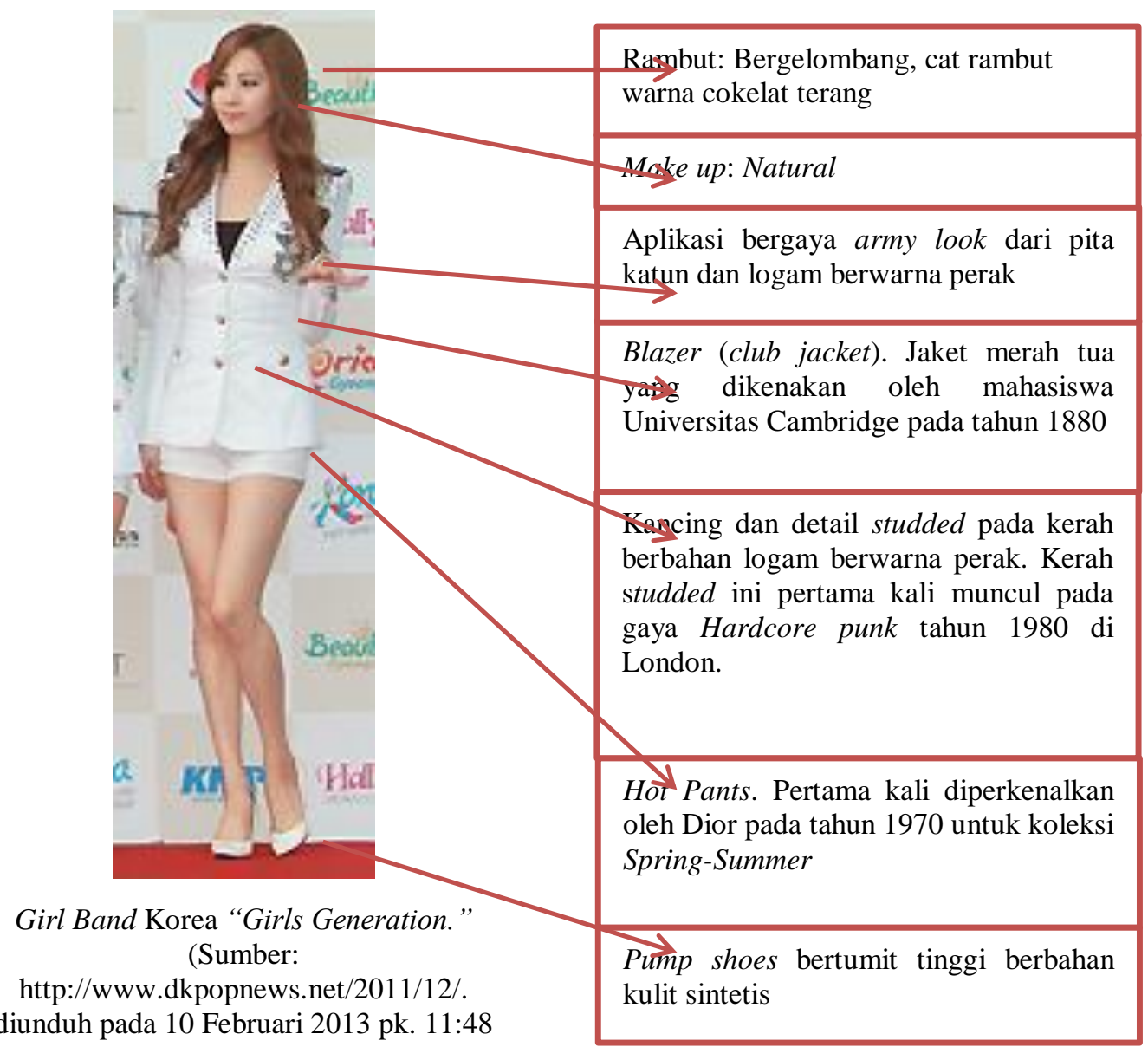

WIB)

1. Component of Fashion:

a. Silhouette/ Siluet:

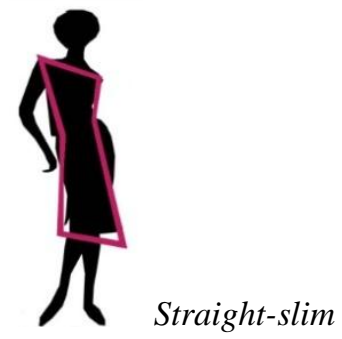

b. Details/Detail:
Hot Pants:

- Opening/Closing: Di depan, dengan zipper dan kancing

Milineris dan Aksesoris:

- Sepatu: Pump shoes bertumit tinggi dari bahan kulit sintetis

c. Texture/ Tekstur:

Tank Top: halus, lembut, lunak

Blazer: kaku, tebal

Hot Pants: kaku, tebal

d. Color/ Warna: 
Tank Top:

- Garis Leher: Bulat

Blazer:

- Kerah: Tailor

- Lengan: Straight

- Saku: Wallet dengan kancing

- Opening/Closing: Di depan, dengan kancing
2. Element of Designs:

a. Fabric/ Bahan:

Tank Top: Kaos

Suit: Katun tebal

Hot Pants: Katun tebal

\section{Objek I.c}

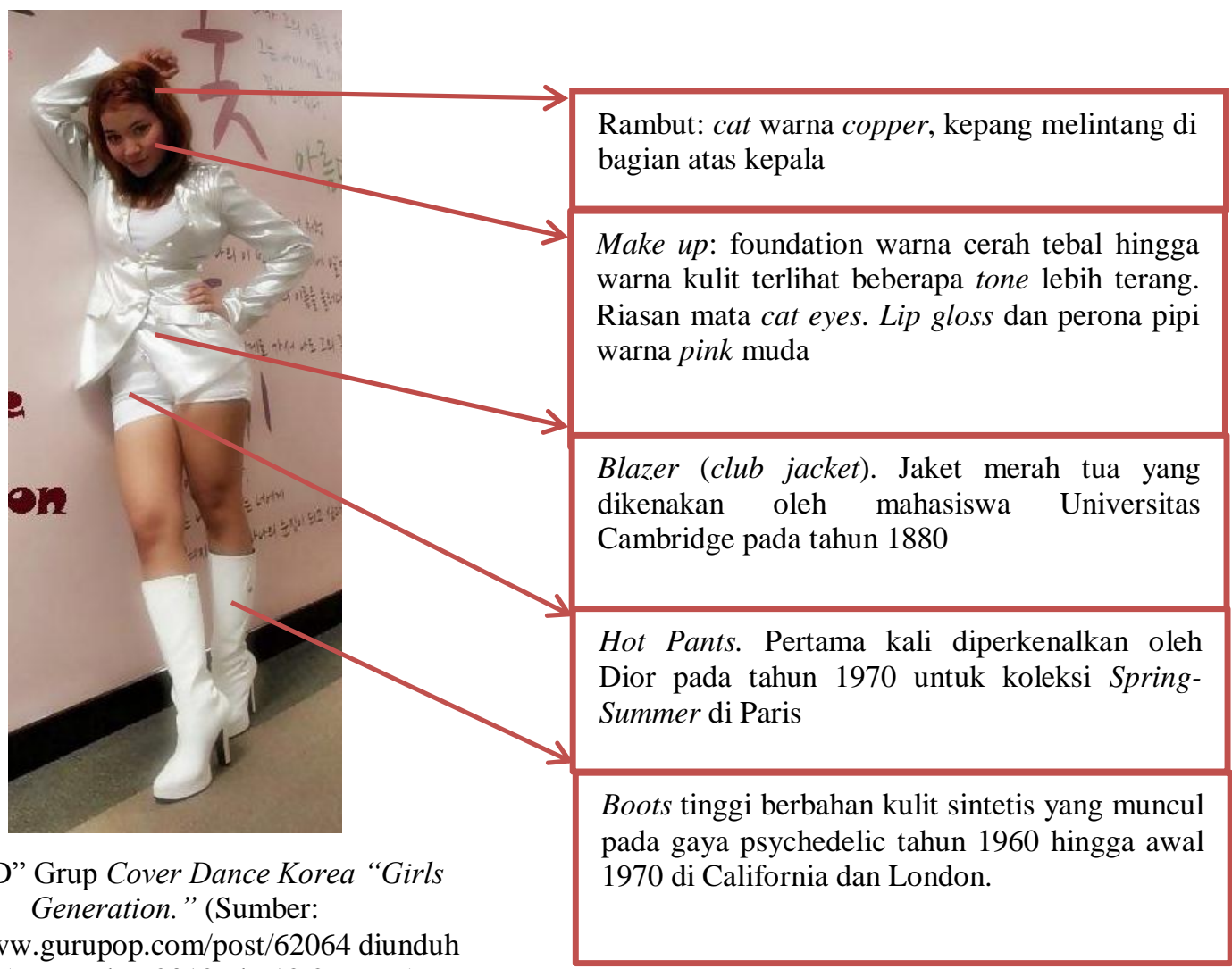

http://www.gurupop.com/post/62064 diunduh pada 5 Desember 2012 pk. 12:27 WIB)

1. Component of Fashion:

a. Silhouette/ Siluet:

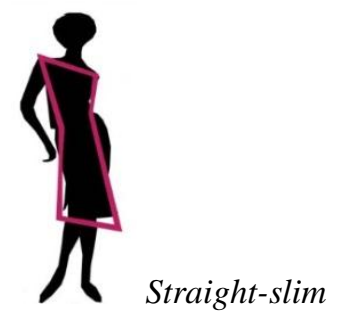

b. Details/Detail:

Tank Top:

- Garis Leher: Bulat

Blazer:

- Kerah: Tailor

- Lengan: Straight

- Saku: Wallet

- Opening/ Closing: Di depan, dengan kancing

\section{Hot Pants:}

- Opening/Closing: Di depan, dengan zipper dan kancing

Milineris dan Aksesoris:

- $\quad$ Sepatu: Boots tinggi dari bahan kulit sintetis

c. Texture/ Tekstur:

Tank Top: halus, lembut, lunak

Blazer: kaku, tebal, mengkilap

Hot Pants: kaku, tebal, mengkilap

d. Color/ Warna:

2. Element of Designs:

a. Fabric/ Bahan:

Tank Top: Kaos

Suit: Shimmering polyester

Hot Pants: Katun 
Objek II. a

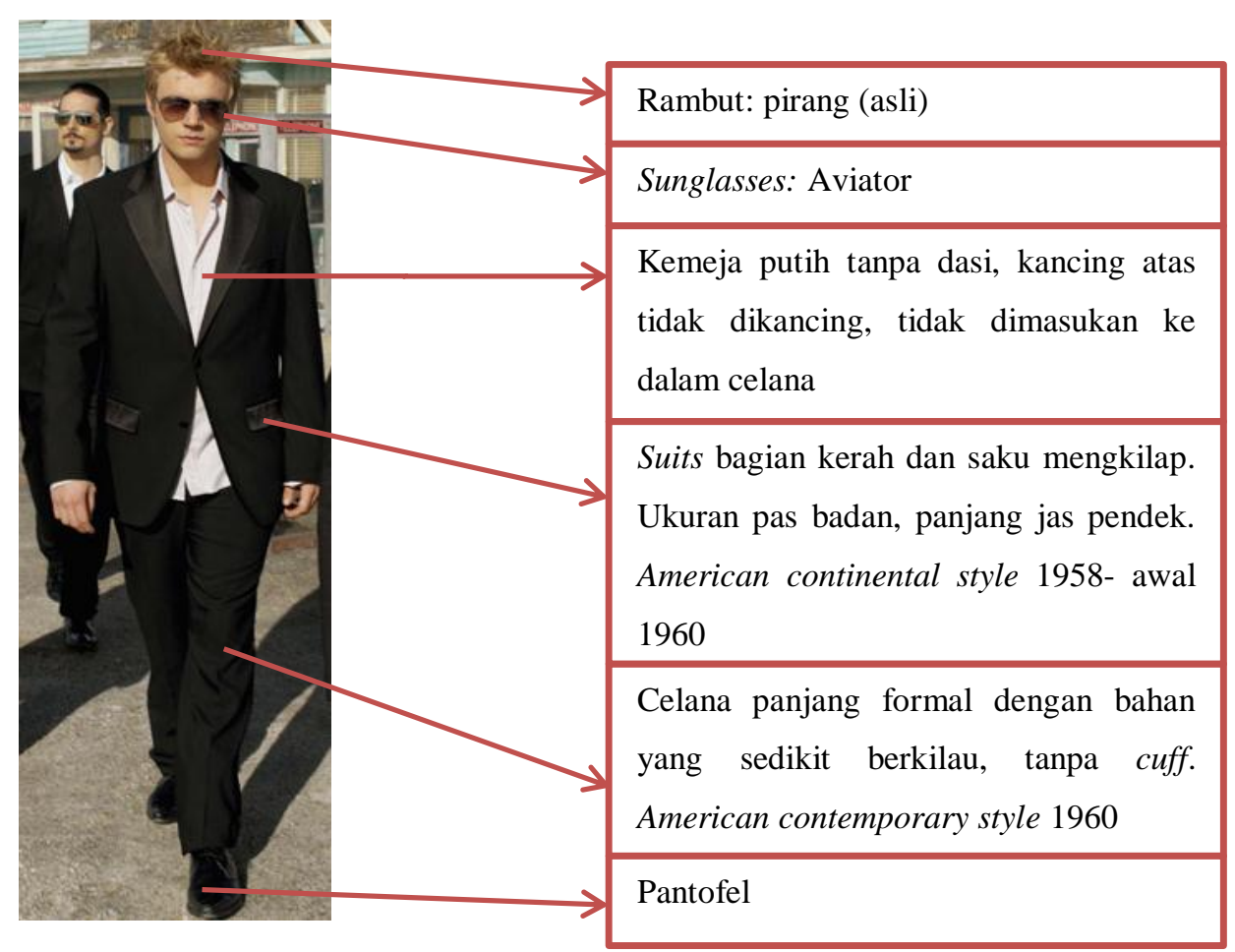

Boy Band barat asal Amerika "Backstreet Boys."

(Sumber: www.ourstage.com diunduh pada 6

Maret 2013 pk. 17:41 WIB)

1. Component of Fashion:

a. Silhouette/ Siluet:

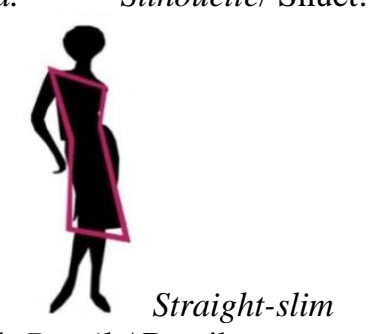

b. Details/ Detail:

Kemeja:

- Kerah: Regular

Point Collar

- Lengan: Straight

- Manset/Cuff:

- Opening/Closing:

Di depan, dengan kancing

Suits:

- Kerah: Tailor

- Lengan: Straight

- Saku: Wallet

- Opening/Closing: Di depan, dengan kancing Celana:

- Opening/Closing: Di depan, dengan zipper dan kancing
Milineris dan Aksesoris:

- Sepatu: Pantofel berbahan kulit sintetis

- Sunglasses: Aviator

c. Texture/ Tekstur:

Kemeja: halus, lembut, lemas

Suits: tebal, kaku, mengkilap

Celana: halus, lembut, lemas

d. Color/ Warna:

2. Element of Designs:

a. Fabric/ Bahan:

Kemeja: Katun

Suits: Katun tebal, bagian kerah dan saku berbahan satin

Celana: Katun tebal 


\section{Objek II. b}

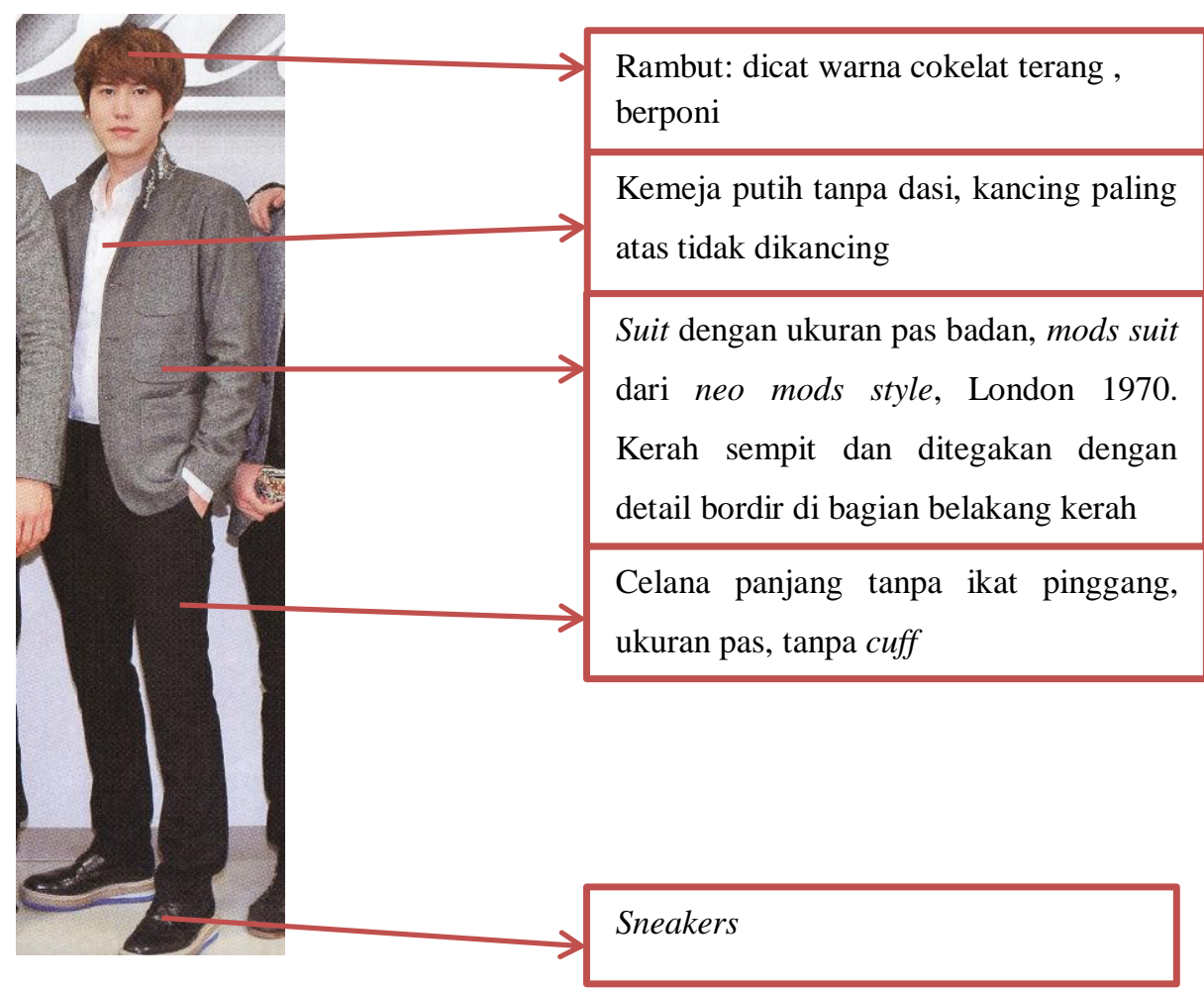

"Super Junior" Boy Band Korea. (Sumber:

icepluscoffee.wordpress.com diunduh pada 15

Maret 2013 pk. 21:31 WIB )

1. Component of Fashion:

a. Silhouette/ Siluet:

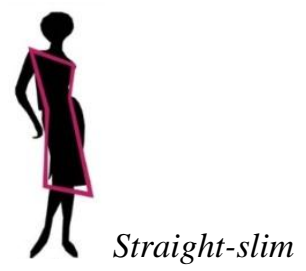

b. Details/ Detail:

Kemeja:

- Kerah: Regular Point Collar

- Lengan: Straight

- Manset/Cuff:

- Opening/Closing: Di depan, dengan kancing Suits:

- Kerah: Tailor

- Lengan: Straight
- Opening/Closing: Di depan, dengan kancing Celana:

- Opening/Closing: Di depan, dengan zipper dan kancing

Milineris dan Aksesoris:

- Sepatu: Sneakers

c. Texture/ Tekstur:

Kemeja: halus, lembut, lemas

Suits: tebal, kaku, mengkilap

Celana: kaku, tebal

d. Color/ Warna:

2. Element of Designs:

a. Fabric/ Bahan:

Kemeja: Katun

Suits: Katun tebal

Celana: Katun tebal 
Objek II. c

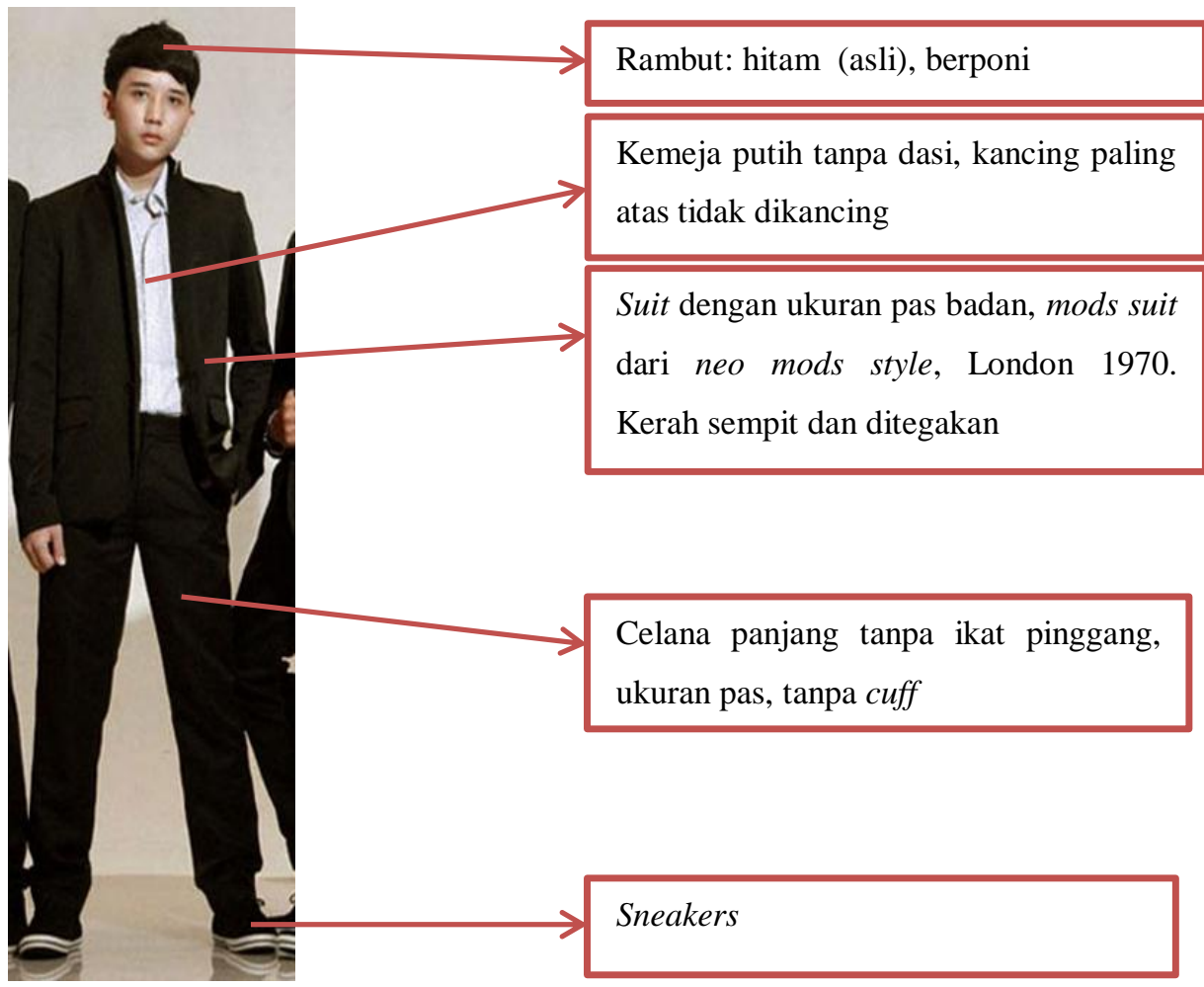

"SM*SH" Boy Band Indonesia. (Sumber:

photopoto.blogspot.com diunduh pada 15 Maret

2013 pk. 22:30 WIB)

1. Component of Fashion:

a. Silhouette/ Siluet:

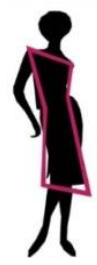

b. Details/Detail:

Kemeja:

- Kerah: Regular Point Collar

- Lengan: Straight

- Manset/Cuff:

- Opening/Closing: Di depan, dengan kancing Suits:

- Kerah: Tailor

- Lengan: Straight

- Saku: Wallet
- Opening/Closing: Di depan, dengan kancing

Celana:

- Opening/Closing: Di depan, dengan zipper dan kancing

Milineris dan Aksesoris:

- Sepatu: Sneakers

c. Texture/ Tekstur:

Kemeja: halus, lembut, lemas

Suits: tebal, kaku, mengkilap

Celana: kaku, tebal

d. Color/Warna:

2. Element of Designs:

a. Fabric/ Bahan:

Kemeja: Katun

Suits: Katun tebal

Celana: Katun tebal 
Berdasarkan komparasi antara objek I.a, objek I.b, dan objek I.c maka dapat ditarik kesimpulan bahwa gaya yang ditampilkan oleh ikon $K$-pop merupakan campuran dari beberapa gaya barat. Gaya tersebut memiliki detail unsur-unsur fashion yang lebih banyak dibandingkan dengan dua gaya lainnya. Gaya ikon K-pop mampu memadu madankan beberapa gaya barat sekaligus. Sedangkan gaya barat dan gaya yang ditampilkan oleh remaja Indonesia memiliki detail yang lebih sederhana. Walaupun, gaya remaja Indonesia cenderung memiliki persamaan yang lebih banyak dengan gaya ikon $K$-pop, namun terjadi penyederhanaan detail. Dari segi warna, ketiganya memilih warna yang hampir sama. Namun, dari segi tata rambut, ikon $K$-pop cenderung memilih warna rambut yang lebih terang, jauh berbeda dengan warna rambut aslinya yang berwarna hitam.

Berdasarkan komparasi antara objek II.a, objek II.b, dan objek II.c maka dapat terlihat bahwa gaya yang ditampilkan oleh ikon $K$-pop memiliki detail yang lebih banyak dibandingkan dengan dua gaya lainnya. Gaya ikon K-pop pada objek II.b juga mengadopsi gaya barat namun menambahkannya dengan detail lain seperti, detail motif di belakang kerah dan beberapa saku dalam satu sisi sekaligus. Gaya ikon K-pop pada objek II.b menampilkan gaya yang berbeda dengan gaya barat dalam mengenakan suits, yaitu menegakkan kerahnya. Tampilan suits yang berbeda ini ditiru oleh gaya remaja Indonesia dalam objek II.c. Berdasarkan komparasi ini, dapat terlihat bahwa gaya remaja Indonesia memiliki lebih banyak persamaan dengan gaya yang ditampilkan oleh ikon $K$-pop. Dari segi warna, ketiganya memilih warna yang hampir sama. Namun, dari segi tata rambut, ikon $K$-pop cenderung memilih warna rambut yang lebih terang, jauh berbeda dengan warna rambut aslinya yang berwarna hitam

\section{KESIMPULAN}

Berdasarkan hasil analisa menunjukan bahwa gaya yang disebut oleh masyarakat Indonesia sebagai gaya Korea sesungguhnya merupakan gaya hasil adopsi dari gaya barat. Walaupun begitu, terdapat perbedaan yang signifikan, yaitu gaya yang ditampilkan oleh ikon K-pop memiliki detail unsur fashion yang lebih banyak dibandingkan dengan gaya barat dan mampu memadukan beberapa gaya barat sekaligus dalam satu tampilan gaya. Selain itu, pemilihan warna untuk tatanan rambut, gaya para ikon $K$-pop pun memilih warna yang cenderung lebih terang dan berbeda jauh dengan warna rambut asli mereka. Pengidentifikasian ini menunjukan bahwa tampilan gaya ikon $K$-pop terkesan lebih berani 
dan ekspresif. Sedangkan gaya barat dan gaya remaja Indonesia cenderung lebih sederhana dan tidak menampilkan banyak detail dalam unsur-unsur fashionnya.

\section{DAFTAR PUSTAKA}

Barnard, Malcolm. 1996. Fashion Sebagai Komunikasi (Fashion as Communication). Yogyakarta: Jalasutra

Barthes, Roland. 1983. The Fashion System. Hill \& Wang/Farrar, Straus \& Giroux

Djelantik, A.A.M. 1999. Estetika Sebuah Pengantar. Bandung: Masyarakat Seni Pertunjukan Indonesia

Frings, Gini Stephen. 1987. Fashion from Concept to Consumer. New Jersey: PrenticeHall

Haldani, Achmad. 1998. Street Style Sebagai Fenomena Budaya dan Pengaruhnya di Indonesia. Tesis Magister Desain. Bandung: Fakultas Seni Rupa dan Desain Institut Teknologi Bandung

Iwabuchi, Koichi dan Huat, Beng Chua. 2008. East Asian Pop Culture: analyzing the Korean Wave. Hong Kong: Hong Kong University Press

Korean Culture and Information Service. 2011. The Korean Wave: A new pop culture phenomenon. Korean Culture and Information Service Ministry of Culture, Sports and Tourism

Martono, John. 2000. Gaya Busana Punk di Bandung (Sebuah Kajian Semiotik). Tesis Magister Desain. Bandung: Fakultas Seni Rupa dan Desain Institut Teknologi Bandung

Piliang, Yasraf Amir. 2004. Dunia yang Dilipat: Tamasya Melampaui Batas-batas Kebudayaan. Jalasutra

Riyanto, Arifah A. 2003. Teori Busana. Bandung: Yapemdo

Siregar, B. S. 2008. Kajian Harajuku Style di Indonesia Ditinjau Melalui Pendekatan Unsur-Unsur Fashion. Tesis Magister Desain. Bandung: Fakultas Seni Rupa dan Desain Institut Teknologi Bandung

Sorapure, Madeleine dan Petracca, Michael. 2001. Common Culture: Reading and Writing About American Popular Culture. New Jersey: Prentice-Hall, Inc.

Stone, Elaine. 2006. The Dynamic of Fashion. New York: Fairchild

Zeshu, Takamura. 1997. Roots of Street Style. Tokyo: Graphic-Sha 